\title{
Reaction of Rice (Oryza sativa) Cultivars to Penetration and Infection by Curvularia tuberculata and C. oryzae
}

Lilian Z. de Luna, Graduate Student, Department of Plant Science, McGill University, 21,111 Lakeshore Road, Ste-Anne-de-Bellevue, Québec, Canada H9X 3V9 and Scholar, International Rice Research Institute, DAPO 7777, Metro Manila, Philippines; Alan K. Watson, Professor, Department of Plant Science, McGill University, and Weed Scientist (Seconded from McGill University), International Rice Research Institute; and Timothy C. Paulitz, Associate Professor, Department of Plant Science, McGill University

\begin{abstract}
de Luna, L. Z., Watson, A. K., and Paulitz, T. C. 2002. Reaction of rice (Oryza sativa) cultivars to penetration and infection by Curvularia tuberculata and C. oryzae. Plant Dis. 86:470-476.

Isolates of Curvularia species were collected from weedy Cyperaceae species and are being evaluated as possible biocontrol agents of sedge weeds in rice (Oryza sativa). Curvularia species have been reported from rice; thus cultivars of rice were tested to determine rice seedling responses to these potential biocontrol agents. All 13 rice cultivars were resistant to Curvularia tuberculata isolate 93-022, 12 were resistant to $C$. tuberculata isolate 93-020, and 7 were resistant to $C$. oryzae isolate 93-061. In the resistant cultivars, lesions on the leaf laminae were small, light to dark brown, with a dry appearance. Spots on the leaf margins and leaf tips were light brown to cream and dry. In the susceptible cultivars, the brown lesions coalesced with necrotic centers. Sporulation was observed in the lesions on susceptible cultivars but not on the resistant cultivars. The histopathology of $C$. tuberculata and $C$. oryzae was studied in two resistant rice cultivars, IR 64 (IRRI Acc. no. 66970) and Norin 21 (IRRI Acc. no. 7686), by light microscopy. C. tuberculata exhibited polar germination beginning at $4 \mathrm{~h}$ postinoculation (HPI); whereas $C$. oryzae was characterized by bipolar germination starting at 2 HPI. Simple terminal or intercalary appressoria were initiated at 24 HPI over stomatal apertures, or rarely, on the epidermal cell walls and bulliform cells. No infection cushions were formed. Penetration occurred by the formation of a fine penetration peg beneath the appressorium. A chlorotic reaction was observed in areas beneath and adjacent to the appressoria and germ tubes and in the infected cells. Resistance of IR 64 and Norin 21 to C. tuberculata and C. oryzae infection was mainly expressed after penetration as a slow and restricted mycelial growth and no sporulation. C. tuberculata isolate 93-022 is the preferred isolate for further study as a biological control agent against Cyperus difformis, C. iria, and Fimbristylis miliacea.
\end{abstract}

Additional keywords: globe fingerush, mycoherbicides, rice flat sedge, small flower umbrella sedge

Rice (Oryza sativa L.) is one of the most important crops in the world, being the staple food for millions of people in Asia. Weeds are considered a major constraint to world rice production and commonly cause yield losses in rice from 10 to $40 \%$ and, occasionally, complete crop failure (31). Poaceae and Cyperaceae species are the major weeds in irrigated rice, and yield

Corresponding author: Alan K. Watson

E-mail: alan.watson@mcgill.ca

Current address of L. Z. de Luna: USDA-ARS, Land Management and Water Conservation, 221 Johnson Hall, Washington State University, Pullman, WA 99164-6421.

Current address of T. C. Paulitz: USDA-ARS, Root Disease and Biological Control Lab, 363 Johnson Hall, Washington State University, Pullman, WA, 99164-6430.

Accepted for publication 17 December 2001.

Publication no. D-2002-0313-01R

(C) 2002 The American Phytopathological Society reductions of 12 to $50 \%$ have been attributed to sedge weeds (1). Current weed management practices of mechanical, cultural, and chemical methods need to be reassessed in the wake of increasing concerns about economical and environmental sustainability of intensive rice production $(31,44)$.

Biological control of weeds may have a place as a component of integrated pest management (IPM) programs for rice in Southeast Asia (44). Two isolates of Curvularia tuberculata Jain, one from diseased Cyperus difformis L. (small flower umbrella sedge) (93-020) and the second from Cyperus iria L. (rice flat sedge) (93-022), and one isolate of Curvularia oryzae Bugnicourt (93-061), from Fimbristylis miliacea (L.) Vahl (globe fingerush) in the Philippines, were evaluated as possible biological control agents for these sedge weeds. Foliar application of conidial suspensions of these three Curvularia isolates killed seedlings of Cyperus difformis, $C$. iria, and Fimbristylis miliacea (See ADDENDUM).
Species of Curvularia occur mostly as tropical and subtropical facultative plant pathogens with teleomorphic states in Cochliobolus and Pseudocochliobolus (37). C. tuberculata is reported as a pathogen of guava fruit (Psidium guajava) (20), citrus (23), sorghum (Sorghum bicolor) (22), sugarcane (Saccharum officinale) (39), coconut (Cocos nucifera) (29), mango (Mangifera indica) (24), Cosmos (9), and purple nutsedge (Cyperus rotundus) (30). C. tuberculata has also been recovered from soil, wood, and fabric $(37,40)$.

Curvularia oryzae was originally reported from rice grains and also causes a fruit rot in okra (Abelmoschus esculentus) (21). C. verruculosa (2), C. cymbopogonis (38), and C. lunata (4) may cause leaf spots on rice under certain conditions, but these diseases are not economically important (33).

Safety of a potential weed biocontrol agent, especially to the crop where it will be used, is one of the primary considerations for bioherbicide development (43). Therefore, it is necessary to demonstrate that these fungal isolates will not cause damage to rice. Information about the resistance mechanisms operating during the pre- and postpenetration stages of the infection process will be important in assessing the compatibility between the weed biological control agent and the crop plant. There is no record of $C$. tuberculata or $C$. oryzae causing a foliar disease on rice. However, $C$. tuberculata and $C$. oryzae have been isolated from rice grains $(3,16)$ and implicated in the black kernel disease of rice along with 12 other Curvularia species $(33,45)$. Black kernel is considered a minor disease of rice and is little studied (45). The mode of pathogen entry and the infection process in black kernel disease have not been elucidated. There is no information on resistance to this disease in different rice cultivars. This work reports the host reactions of seedlings of several rice cultivars to inoculations with $C$. tuberculata and $C$. oryzae. The histological responses of highly to moderately resistant cultivars of rice to the three Curvularia isolates were also studied.

\section{MATERIALS AND METHODS}

Fungal isolates. $C$. tuberculata was isolated from diseased Cyperus difformis 
(isolate 93-020) and also from diseased $C$. iria (isolate 93-022) from Lian, Batangas, Philippines. C. oryzae (isolate 93-061) was obtained from diseased $F$. miliacea from Manicahan, Zamboanga, Philippines. All fungal isolates were cultured on halfstrength potato dextrose agar ( $\left.1 \frac{2}{2} \mathrm{PDA}\right)$ plates for initial observation and later stored on agar-oil slants and/or in soil cultures.

Host plants. Seeds of 13 rice cultivars were obtained from the International Rice Research Institute (IRRI) Genetic Resources Center and included indica, japonica, and javanica types as well as IRRI hybrid cultivars. Rice cultivars were chosen on the basis of their contrasting agronomic traits. Seeds of Cyperus difformis, $C$. iria, and $F$. miliacea were obtained from mature plants in the rice fields in the vicinity of Los Baños. Seeds of rice and weeds were germinated in petri dishes lined with moist filter paper. One-week-old seedlings were transplanted into $10-\mathrm{cm}$-diameter standard plastic pots filled with field soil (Maahas clay, Suborder Haplustic, Order Alfisol). The pots were then placed in a large pushcart, and a 2- to 3-cm layer of water was maintained in the pushcart to keep the soil moist. The seedlings were maintained in the greenhouse at 35/25 \pm $5^{\circ} \mathrm{C}$ day/night temperature.

Preparation and application of inoculum. Agar plugs from 1-week-old cultures of $C$. tuberculata and $C$. oryzae were used to seed $1 / 2$ PDA plates for the mass production of the inoculum. Seeded plates of isolates 93-020 and 93-022 were incubated in the dark at $28^{\circ} \mathrm{C}$, while cultures of 93 061 were maintained under continuous light $\left(30 \mu \mathrm{E} \cdot \mathrm{m}^{-1} \cdot \mathrm{s}^{-1}\right)$ at $28^{\circ} \mathrm{C}$. Spore suspensions were prepared by flooding each dish with distilled water and lightly scraping the surface of the colony with a clean glass slide or a camel's hair brush. The suspension was filtered through cheesecloth to separate mycelial fragments from the conidia. Spore concentration was determined using a hemacytometer, and 2week-old seedlings were sprayed at the rate of $1 \times 10^{8}$ conidia $\mathrm{m}^{-2}$. Tween 20 (oxysorbic [20 POE] polyoxyethylene sorbitan monolaurate) was added at the rate of two drops per $100 \mathrm{ml}$ of spore suspension. The suspensions were applied with an atomizer connected to a pressure source. At this stage, rice, Cyperus difformis, and C. iria had three to four expanded leaves, and $F$. miliacea had five to six leaves. Control plants were sprayed with distilled water with Tween 20.

The control and inoculated seedlings were incubated in dew chambers in the dark at $28^{\circ} \mathrm{C}$ and $100 \%$ relative humidity $(\mathrm{RH})$ for $24 \mathrm{~h}$ and then transferred to the mist room of the greenhouse at 24 to $28^{\circ} \mathrm{C}$ and 80 to $95 \%$ RH (47). The experiment was a completely randomized design with six replications. The experiment was repeated once.
Evaluation of varietal response to $C$. tuberculata and $C$. oryzae. The inoculated and control plants were scored at 7 and 14 days after inoculation (DAI) using a key (Table 1) modified from Mardinus (26). Symptom expression on rice cultivars did not change from the 7 DAI to the 14 DAI observation, thus only the 7 DAI data are presented. Scores for each of the three isolates were analyzed using the KruskallWallis ANOVA on ranks (SigmaStat for IBM PC, version 1.0, Jandel Scientific Corporation, 1992-1994). The reactions of rice seedlings were reported as median scores. Results of the two trials were pooled as homogeneity of variance was confirmed by Bartlett's test (10). Plant height differences, if present, were evaluated visually. Relative sporulation of the Curvularia isolates was assessed by excising leaf pieces with lesions, placing them in moist chambers, and observing microscopically after 24,48 , and 72 h. Sporulation was visually rated as sparse, moderate, or heavy.

Histopathology of infection. The third and fourth leaves of IR 64 and Norin 21 rice from infected and uninfected (control) plants were randomly harvested at 2, 4, 8, $16,20,24,36,48,72,96,120,144$, and $168 \mathrm{~h}$ after inoculation (HPI). Two sets of leaf samples were obtained: the first for whole leaf clearing and the second for paraffin imbedding. Leaf segments for whole leaf clearing were placed into vials containing 70 parts ethanol:30 parts glacial acetic acid, while the leaf segments for cross-sectioning were fixed in formaldehyde-acetic acid-alcohol solution (FAA) (17). Leaf samples obtained after 2 and 4 HPI were observed under the microscope for spore deposition before they were subjected to leaf clearing. Twenty or more 1$\mathrm{cm}$ leaf segments from the leaf tips, the middle portions of the lamina, and the leaf bases from each isolate-cultivar combination were examined.

Leaf segments were immersed several times in the alcohol-acetic acid clearing solution until they appeared translucent, and then stained in lactophenol-acid fuchsin for 15 min or until a good contrast was achieved between the epidermal cells (colorless) and the fungal pathogen (deep pink) (6). Stained tissues were dipped in lactophenol to remove excess stain and mounted on glass slides using 50\% glycerin. Microscopic observations were conducted and photographs were taken using a compound microscope mounted to a Nikon 35-mm camera.

Leaves for cross-sectioning were prepared following the method of Johansen (17). Twenty or more leaf segments from each of the isolate-cultivar-harvest time combinations were dehydrated in a graded ethanol-tertiary butyl alcohol series, cleared, and then infiltrated with Paraplast (Fisher Scientific, Montreal, QC) in a $56^{\circ} \mathrm{C}$ oven. After three changes, they were embedded in the same medium and sectioned using a rotary microtome. The sections (12 $\mu \mathrm{m}$ thick) were affixed to clean glass slides using egg albumin and stained with safranin-fast green. Microscopic examinations were performed and photographs taken as described above.

\section{RESULTS}

Evaluation of varietal responses to $C$. tuberculata and $\boldsymbol{C}$. oryzae. The response of rice cultivars to Curvularia isolates 93 020, 93-022, and 93-061 ranged from immune to susceptible, but most cultivars were resistant to the isolates (Fig. 1A to C). However, most inoculated rice seedlings developed only small leaf spots and browning of the leaf tips and margins, indicating an incompatible disease reaction. Lesions were formed only on fully expanded leaves and were first observed between 3 and 5 DAI, demonstrating susceptibility of older leaves. Younger leaves that unfolded after inoculation did not show any symptoms and remained healthy throughout the experimental period. The leaf tips and margins of susceptible rice cultivars were the most vulnerable parts to invasion as necroses were concentrated in these areas. Clumps of conidia were trapped by trichomes present on these sites, thus increasing the probability of infection. In resistant rice cultivars, leaf tips and margins were also invaded, but appeared dry and cream to light brown.

C. oryzae (93-061) was more pathogenic to the rice cultivars tested than the two

Table 1. Disease severity key used to score the reaction of rice seedlings to three isolates of Curvularia $^{\mathrm{a}}$

\begin{tabular}{lll}
\hline Score & Host reaction & Description \\
\hline 0 & I - immune & $\begin{array}{l}\text { No visible symptoms } \\
\text { Few to many brown specks, } 0.5 \text { to } 1.0 \mathrm{~mm} \text { in diameter, } \\
\text { grayish-green or light brown leaf tips } \\
\text { Discrete brown lesions with or without chlorotic halo, } \\
1.0 \text { to } 2.0 \mathrm{~mm} \text { long, brown leaf tips and margins } \\
\text { Many brown spots, } 2.0 \text { to } 3.0 \mathrm{~mm} \text { long, a few lesions } \\
\text { coalescing, brown leaf tips and margins } \\
\text { Many lesions with necrotic centers, } 3 \text { to } 5 \mathrm{~mm} \text { long, } 10 \\
\text { to 50\% of leaf area killed } \\
\text { Numerous large and expanding lesions, more than } 50 \% \\
\text { of leaf area killed, plant collapsed }\end{array}$ \\
\hline
\end{tabular}

${ }^{a}$ Modified from Mardinus (26). 

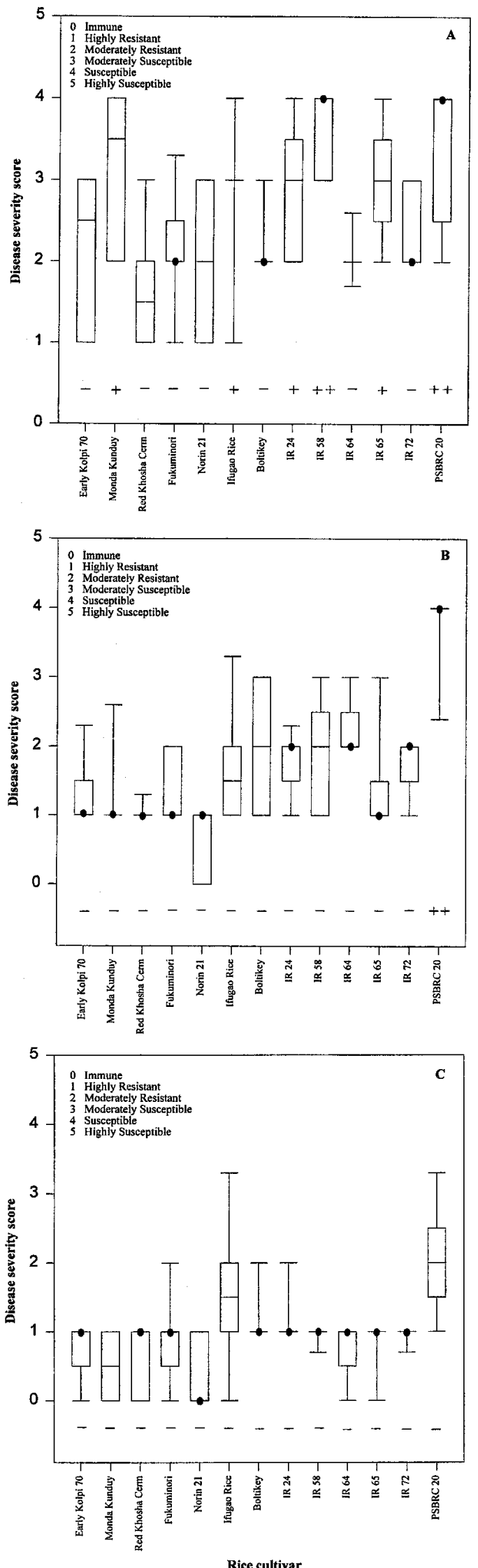

Fig. 1. A, Disease severity score of rice (Oryza sativa) cultivars inoculated with Curvularia oryzae isolate 93-061. B, Disease severity score of rice cultivars inoculated with Curvularia tuberculata isolate 93020. C, Disease severity score of rice cultivars inoculated with C. tuberculata isolate 93-022. Seven days after inoculation. Data represent median scores from two trials. Boxed area represents the 25th and 75 th percentile, a line within the box indicates the median, and the whiskers represent the 10th and 90th percentile. The median is indicated by a dot when it occurs at the border of the boxed area. Sporulation is indicated by - (no sporulation), + (sparse sporulation), or ++ (moderate sporulation). isolates of C. tuberculata. Of the 13 cultivars, two were susceptible, four were moderately susceptible, six were moderately resistant, and one was highly resistant to $C$. oryzae (Fig. 1A). By comparison, only one variety was susceptible to $C$. tuberculata isolate $93-020$ and the other 12 were moderately to highly resistant (Fig. 1B); meanwhile, all of the 13 cultivars were moderately to highly resistant to $C$. tuberculata isolate 93-022 (Fig. 1C).

There was no mortality associated with disease development in any of these rice cultivars. Seven days after inoculation, slight stunting was evident in those cultivars expressing susceptibility to the Curvularia isolates. Sparse to moderate sporulation from the necrotic spots was detected in the susceptible, but not in the resistant, cultivars (Fig. 1A to C). Untreated rice and weed seedlings were healthy and did not develop any symptoms. However, when Cyperus difformis, $C$. iria, and $F$. miliacea were inoculated with their respective Curvularia pathogen, leaf spots developed after 3 days and rapidly coalesced to form large blighted areas. The infected weeds eventually collapsed and died 7 to 14 DAI.

Histopathology of infection. Reactions of IR 64 and Norin 21 to the Curvularia isolates ranged from moderately to highly resistant (Fig. 1A to C). The infection process of the three isolates was similar, and the histopathological reactions of the highly resistant rice cultivars differed from the moderately resistant ones only with respect to the number and size of lesions produced. Necrotic areas in the leaf tips and margins also were observed more frequently on moderately resistant cultivars.

Responses to $C$. tuberculata (isolates 93-020 and 93-022). Spores germinated after 4 h on IR 64 and Norin 21, and germ tubes emerged only from the hilar or the apical ends of the spore. By 24 HPI, most of the spores had germinated. The direction of germ tube growth was predominately $( \pm 75 \%)$ random, although some were found to follow the long axis of the epidermal cells. Appressoria were mainly ( $\pm 85 \%)$ formed over the stomata (Fig. 2A) beginning 24 HPI. These prepenetration events of the two isolates of $C$. tuberculata in IR 64 and Norin 21 were similar to those that occurred in the sedge weed hosts (L. Z. de Luna, A. K. Watson, and T. C. Paulitz, unpublished). After penetration, infection hyphae were observed within the epidermal cells, but their growth was restricted and slow. Yellowing and browning of the infected cell(s) was pronounced. Small lesions were present on the leaf lamina (Fig. 2B) at $168 \mathrm{HPI}$.

In Norin 21, appressoria developed preferentially over stomata, but some were formed over the epidermal or bulliform cells (Fig. 2C). They were round, oval, or clavate and 3 to $7 \mu \mathrm{m}$ in diameter. Some epidermal cells in the vicinity of the germ 
tubes or appressoria became granular in appearance (Fig. 2D).

C. tuberculata isolate 93-022 caused small lesions in the epidermal and mesophyll cells of Norin 21 (Fig. 2E). Although this rice variety had a median disease severity score of " 0 " (immune) when inoculated with 93-022, some plants developed tiny flecks that became more apparent when histological examinations were performed. Cross-sections of the lesions revealed that the growth of the infection hyphae was sparse and that a yellowing reaction was present at the border of the lesion (Fig. 2E). This indicates that Norin 21 exhibits a high degree of resistance to isolate 93-022. No sporulation was observed in IR 64 or in Norin 21 when inoculated with these $C$. tuberculata isolates.

Responses to $C$. oryzae (isolate 93061). The reactions of IR 64 and Norin 21 to $C$. oryzae were similar. Spores germinated within $2 \mathrm{~h}$, and germ tube growth was both perpendicular and parallel to the epidermal cells. Appressorium formation began $24 \mathrm{~h}$ after inoculation and preferentially developed over the stomatal region, although a few were formed over the epidermal cells. Appressoria were round or clavate (Fig. 2F). Attempted penetration was immediately accompanied by the yellowing of the guard cells or epidermal cells underneath the infection structure. Infection hyphae were detected within the leaf tissues (Fig. 2G).

A narrow penetration peg (Fig. $2 \mathrm{H}$ ) accomplished the penetration process. When the appressorium was removed, a small hole was observed where the penetration peg entered the cell (Fig. 2H). The upper cuticle where the appressorium was formed appeared yellow, while the lower cuticle and the rest of the upper cuticle remained red from the safranin stain (Fig. 2H). A stoma directly underneath a branched germ tube appeared yellow and granular (Fig. 2I). Initially, yellowing was confined in the intercellular regions of the mesophyll layer (Fig. 2I), but it later spread intercellularly even without evidence of penetration (Fig. 2J).

Immediately after penetration, primary infection hyphae were formed and grew within the epidermal cells. The spread of the fungus to the neighboring cells was, however, slow. By 72 HPI, only a few cells in the mesophyll region closest to the epidermis had been infected and further colonization of this region was slow. Small, brown spots were produced at 168 HPI consisting of collapsed epidermal and mesophyll cells, but no sporulation occurred in these lesions.

\section{DISCUSSION}

A compatible disease reaction occurs when symptoms are clearly expressed as opposed to an incompatible reaction where the symptoms do not develop and the effect on the plant is minimal (25). When inoculated with their respective Curvularia pathogens, Cyperus difformis, C. iria, and $F$. miliacea rapidly developed coalescing foliar lesions and a blighting reaction that resulted in plant death within 1 to 2 weeks. However, the effect of the pathogens on rice was, for the most part, an incompatible reaction.

A high degree of resistance was exhibited by rice to $C$. tuberculata and $C$. oryzae. $C$. oryzae was the most virulent to the rice cultivars, although half of the cultivars tested were resistant. C. tuberculata was less virulent, with most of the rice cultivars resistant to isolate 93-020 and all resistant to isolate 93-022. Host specialization has apparently occurred in C. tuberculata. A C. tuberculata isolate from Rangpur lime (Citrus limonia) was not pathogenic to rice (Taichung Native 1), but it caused severe blighting and death of a local maize variety (23). In our study, isolate 93-022 from Cyperus iria was less pathogenic to rice compared with isolate 93-020 from $C$. difformis.

Sporulation of the Curvularia isolates did not occur on the resistant rice cultivars. Although sporulation is never an isolated component of resistance (5), it is often the most sensitive indicator of race-specific (vertical) and race-non-specific (horizontal) resistance (18). In most cases, inhibited infection and colonization are accompanied by reduced sporulation (5). Rice cultivars that were resistant to the Curvularia isolates, such as Norin 21 and Red Khosha Cerma, were characterized by limited lesion development and inhibition or absence of sporulation. Moderately susceptible to susceptible rice cultivars such as IR 58 and PSBRC 20 exhibited more leaf necrosis and sparse to moderate sporulation.

Older leaves were more susceptible than younger leaves to inoculations of $C$. tuberculata and $C$. oryzae. Resistance to pathogens is often affected by the developmental stage of the plant or of the plant organ (8), with older plants appearing to be more resistant (15), although this is not always the case (35). Lesions on the leaf margins grew inward from the edges of the leaf. In rice, hydathodes are present at the margins and leaf tips (14), and these could have facilitated the entry of the fungus. Hydathodes serve to secrete excess water from the interior of the leaves but may also provide an opening on the epidermis through which pathogens can enter (32).

Surface development of $C$. tuberculata and $C$. oryzae on the leaves of IR 64 and Norin 21 did not differ and was similar to the development events recorded for the sedge hosts (L. Z. de Luna, A. K. Watson, and T. C. Paulitz, unpublished). Sivanesan (40), however, reported that $C$. tuberculata exhibited bipolar germination and sometimes lateral germination. There were no obvious signs of orientation for the direction of the germ tube growth. Germ tubes developed perpendicularly and parallel to the long axis of the rice epidermal cells, but there was generally less branching than observed on the sedge host's leaves.

Only simple appressoria were formed in the rice hosts treated with any one of the three isolates. Compound appressoria or infection cushions as described by Emmett and Parberry (7) were not observed. It is possible that the different surface architecture of rice plants did not provide the appropriate stimulus for the infection cushion formation.

Most appressoria in this study were formed over the stomatal aperture in rice, and penetration of epidermal cell walls occurred infrequently. This is in contrast to what occurs in sedge hosts, where epidermal cell wall junctions were the preferred penetration sites. Since there was no indication of the orientation of the germ tube growth in both $C$. tuberculata and $C$. oryzae in rice, it is possible that a substance present in the area of the stomatal aperture could be the stimulus for appressorium formation. Evidence of the involvement of chemical stimuli in appressorium formation has been identified for the rust fungi and include $\mathrm{K}^{+}$and $\mathrm{Ca}^{+}$ions (19), sucrose (13), and a volatile compound from the host plants (11).

The occasional penetration of the epidermal cells could be due to the leaching of stimulatory substance(s) from cuticular breaks that resulted from the opening and closing of the stomata (46). Few appressoria were formed over bulliform cells. Bulliform cells have been reported as the preferred penetration sites for Pyricularia oryzae (12).

Stomata occur on the adaxial and abaxial sides of the rice leaf in files between the veins (14), while in the sedges, they are found only on the abaxial side (28). Huge hydathodes or hydropores occur along the leaf margins at the edges of the rice leaf blade. These structures have pore diameters more than twice as large as those of ordinary stomata and are involved in the guttation of water from the leaf when active water uptake is occurring in the plants (14). Since the lesions observed along the leaf margins developed from the edge to the inner part of the leaf lamina (Fig. 2G), this suggests that hydathodes are also the entry sites of $C$. tuberculata and $C$. oryzae into rice.

In sedge hosts, infection structures were observed between 8 and $12 \mathrm{HPI}$, but in rice, appressoria did not form until 20 to 24 HPI. The repression of the ability of pathogens to form infection structures can be viewed as a defense mechanism to disease (27).

The mode of penetration of rice by the three isolates followed the same pattern as that observed in the sedge hosts. A fine penetration peg that emerged from the appressorium (Fig. 2C) accomplished penetration. Both mechanical force and enzymatic action were apparently required 

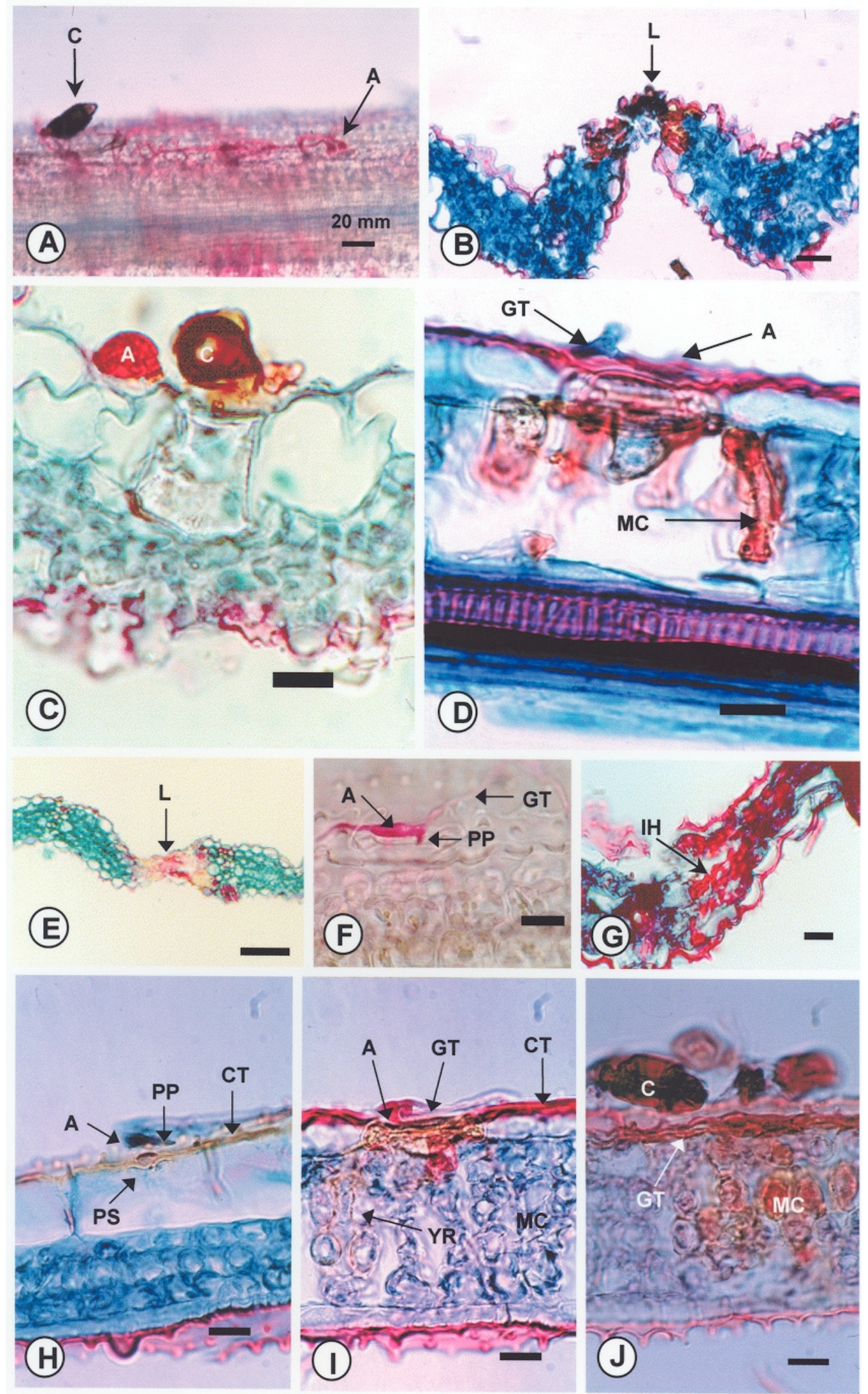

Fig. 2. Histopathology of infection of Oryza sativa cvs. IR64 and Norin 21 by Curvularia tuberculata (isolates 93-020 and 93-022) and C. oryzae (isolate 93-061). A, Appressorium (A) formation on stomata of cv. IR64 by isolate 93-022, 24 hours postinoculation (HPI). B, Transverse section of a small lesion (L) on the leaf blade of cv. IR64 by isolate 93-020, 72 HPI. C, Transverse section of a conidium (C) and appressorium (A) of isolate 93-020 over bulliform cells of cv. Norin 21, 24 HPI. D, Granular appearance of mesophyll cells (MC) of cv. Norin 21 beneath a stomate with a germ tube (GT) and an appressorium (A) from isolate 93-022, 72 HPI. E, Restricted lesion (L) formation in cv. Norin 21 by isolate 93-022 at 168 HPI. F, Penetration of a stomate by a penetration peg (PP) arising from an appressorium (A) of isolate 93-061 in cv. IR64, 36 HPI. G, Infection hyphae (IH) of isolate 93-061 in transverse leaf section of cv. IR64, $144 \mathrm{HPI}$. H, A hole is revealed in the penetration site (PS) where an appressorium (A) of isolate 93-061 penetrated the epidermal cell wall of cv. Norin 21, 72 HPI. Note yellowing of cuticle (CT). I, Appressorium (A) of isolate 93-061 penetrating a stomate that has turned yellow. Note yellowing reaction (YR) in some mesophyll cells (MC) underneath the invaded stomata of cv. Norin 21, $72 \mathrm{HPI}$. EC, epidermal cell; GT, germ tube; CT, cuticle. J, Yellowing reaction in some mesophyll cells (MC) of cv. Norin 21 underneath conidia (C) and germ tubes (GT) of isolate 93-061, 72 HPI. 
for penetration since a hole was present (Fig. 2D) and yellowing of the cuticle beneath and adjacent to the appressorium was observed (Fig. 2F). Differential staining of the area beneath, adjacent to, or just ahead of the hyphal tips and infection structures has been previously reported (41).

After penetration, primary infection hyphae were observed but their growth was restricted and slow. Restricted colony and lesion formation are considered components of resistance, since these reflect the growth rate of the pathogen in the host and therefore its spore production (34). In the resistant type of host-pathogen combinations of Peta rice and Philippine races of $P$. oryzae, browning of the tissues occurred at a faster rate, inhibiting lesion formation, which resulted in a resistant lesion type (42). The expression of race-specific resistance to $P$. oryzae involves the inhibition of fungal hyphae growth, accompanied by light browning of epidermal cells in rice leaves (36).

In this study, partial resistance of IR 64 and Norin 21 to $C$. tuberculata and $C$. oryzae was operative during the prepenetration phase as expressed in the delay of the initiation of infection structure formation. Postpenetration resistance mechanisms were expressed as inhibition of fungal growth after penetration and lack of sporulation.

Species of Curvularia are commonly saprophytic or weakly pathogenic, and rarely virulent (45). Seshadri et al. (39) noted that dense spotting and extensive blighting of sugarcane leaves from a $C$. tuberculata infection was only observed on a few severely affected plants, and concluded that the disease was of negligible importance. It is possible that Curvularia leaf spots do occur on rice in fields, but the disease is so minor that it has gone completely unnoticed. The implication of minor foliar lesions on rice in the appearance of black kernel is not known. Similarly, the possible role of Curvularia blights of sedge weeds in the rice field on black kernel disease of rice is unknown.

This study has been part of a biological weed control project, and although extreme host specificity is not needed for indigenous plant pathogens that are to be developed as bioherbicides, the pathogens must be "sufficiently safe" to desirable plant species (43). Resistance to $C$. tuberculata isolate 93-022 was expressed in all rice cultivars from the three ecogeographic races or types (indica, japonica, and javanica). Further studies of isolate 93-022 are needed to clearly determine its host range, to evaluate its safety and potential as a biocontrol agent for sedge weed species in rice production.

\section{ADDENDUM}

After this paper was accepted, the following cited paper was published:

de Luna, L. Z., Watson, A. K., and Paulitz, T. C.
2002. Seedling blights of Cyperaceae weeds caused by Curvularia tuberculata and $C$. oryzae. Biocontrol Sci. Technol. 12:165-172.

\section{ACKNOWLEDGMENTS}

This work was conducted under a memorandum of agreement between the International Rice Research Institute (IRRI) and McGill University. This work was funded in part by the United Nations Development Program (UNDP) grant GLO/91/001/A/01/42 to IRRI, by the Canadian International Development Agency through the CGIAR-Canada Linkage Fund, and by Natural Sciences and Engineering Research Council of Canada (NSERC) Operating Grants to AKW. The authors acknowledge D. Donnelly for use of equipment and facilities at McGill University and R. Masangkay for reviewing the manuscript.

\section{LITERATURE CITED}

1. Ampong-Nyarko, A., and De Datta, S. K. 1991. A Handbook for Weed Control in Rice. International Rice Research Institute, Manila, Philippines.

2. Aulakh, K. S. 1966. Rice, a new host of Curvularia verruculosa. Plant Dis. Rep. 50:314316.

3. Bugnicourt, F. 1950. Les espèces du genre Curvularia isolées des semences de riz. Rev. Gén. Bot. 57:65-77.

4. Chu, C. L., and Chen, C. C. 1973. Physiological study of Curvularia lunata and its pathogenicity to rice plant. J. Taiwan Agric. Res. 22:213-220.

5. Cohen, Y., and Rotem, J. 1987. Sporulation of foliar pathogens. Pages 315-333 in: Fungal Infection of Plants. British Mycological Society Symposium Series 13. G. F. Pegg and P. G. Ayres, eds. Cambridge University Press, Cambridge, UK.

6. Dhingra, O. D., and Sinclair, J. B. 1985. Basic Plant Pathological Methods. CRC Press, Boca Raton, FL.

7. Emmett, R. W., and Parberry, D. G. 1975. Appressoria. Annu. Rev. Phytopathol. 13:147167.

8. Eskes, A. B., and Toma-Braghini, M. 1982. The effect of leaf age on incomplete resistance of coffee to Hemileia vastatrix. Neth. J. Plant Pathol. 88:219-230.

9. Ghosh, R. N., and Gupta, S. 1980. Two new host records from India. Indian Phytopathol. 33:498-500.

10. Gomez, K. A., and Gomez, A. A. 1984. Statistical Procedures for Agricultural Research. 2nd ed. John Wiley \& Sons, New York.

11. Grambow, H. J. 1977. The influence of leaf volatile constituents on the in vitro differentiation and growth of Puccinia graminis $\mathrm{f}$. $\mathrm{sp}$. tritici. Phytopathol. Z. 85:361-372.

12. Hau, F. C., and Rush, M. C. 1982. Preinfectional interactions between Helminthosporium oryzae and resistant and susceptible rice plants. Phytopathology 72:285-292.

13. Hoch, H. C., and Staples, R. C. 1987. Structural and chemical changes among the rust fungi during appressorium development. Annu. Rev. Phytopathol. 25:231-247.

14. Hoshikawa, K. 1989. The Growing Rice Plant: An Anatomical Monograph. Nosan Gyosan Bunka Kyokai (Nobunkyo). Tokyo, Japan.

15. Hyde, P. M. 1977. The effect of leaf age on infection of wheat seedlings by Erysiphe graminis on subsequent colony development. Phytopathol. Z. 88:299-305.

16. Jain, B. L. 1962. Two new species of Curvularia. Trans. Br. Mycol. Soc. 45:539-544.

17. Johansen, D. A. 1940. Plant Microtechnique. McGraw-Hill Book Co., New York

18. Johnson, R., and Taylor, A. J. 1976. Spore yield of pathogens in investigations of the race specificity of host resistance. Annu. Rev.
Phytopathol. 14:97-119.

19. Kaminsky, S. G. W., and Day, A. W. 1984. Chemical induction of infection structures in rust fungi. II. Inorganic ions. Exp. Mycol. 8:193-201.

20. Kapoor, I. J., and Tandon, R. N. 1971. Occurrence of Curvularia tuberculata Jain on stored fruits of Psidium guajava L. Sydowia 24:201-202.

21. Lal, B., and Goel, D. 1989. A new rot of Abelmoschus esculentus. Indian Phytopathol. 42:482.

22. Lambat, A. K., and Ram, A. 1969. Seed-borne infection of Curvularia causing a new blight disease of Jowar. Indian Phytopathol. 22:282284.

23. Lele, V. C., Raychaudhuri, S. P., Bhalla, R. B., and Ram, A. 1968. Curvularia tuberculata, a new fungus causing die-back disease of citrus in India. Indian Phytopathol. 21:66-72.

24. Lele, V. C., Singh, J., Rai, S. N., and Kandhari, J. 1981. Occurrence of a new blight disease of mango caused by Curvularia. Curr. Sci. 50:464-465.

25. Lucas, J. A. 1998. Plant Pathology and Plant Pathogens. 3rd ed. Blackwell Science Ltd., London.

26. Mardinus. 1983. Pathogenicity test of three isolates of Drechslera oryzae (Breda de Haan) Subram. \& Jain on rice seedlings. Pages 215218 in: Proc. Sympos. Pest Ecol. Pest Manag. BIOTROP Special Publ. no. 18. SEAMEO Regional Center for Tropical Biology, Bogor, Indonesia.

27. Marshall, D. S., and Rush, M. C. 1980. Relation between infection by Rhizoctonia solani and $R$. oryzae and disease severity in rice. Phytopathology 70:941-946.

28. Metcalfe, C. R. 1971. Anatomy of the Monocotyledons. V. Cyperaceae. Clarendon Press, Oxford, UK.

29. Mishra, D., and Singh, N. 1987. Two new leaf diseases of coconut seedlings caused by Curvularia spp. Indian J. Plant Pathol. 5:208-209.

30. Misra, A. P., Prakash, O., Mishra, B., and Dutta, K. K. 1973. A new leaf spot disease of motha (Cyperus rotundus L.) caused by Curvularia tuberculata. Indian Phytopathol. 26:165-167.

31. Moody, K. 1995. Sustainability in rice weed management. Pages 93-103 in: Proc. Asian Pacific Weed Sci. Soc. Conf. 15th. Vol. IA.

32. Muchovej, J. J., and Couch, H. B. 1987. Colonization of bentgrass turf by Curvularia lunata after leaf clipping and heat stress. Plant Dis. 71:873-875.

33. Ou, S. H. 1985. Rice Diseases. 2nd ed. Great Britain: C.A.B. International. Wallingford, UK.

34. Parlevliet, J. E. 1979. Components of resistance that reduce the rate of epidemic development. Annu. Rev. Phytopathol. 17:203-222.

35. Pelletier, J. R., and Fry, W. E. 1989. Characterization of resistance to early blight in three potato cultivars: Incubation period, lesion expansion rate, and spore production. Phytopathology 79:511-517.

36. Peng, Y.-L., and Shishiyama, J. 1988. Temporal sequence of cytological events in rice leaves infected with Pyricularia oryzae. Can. J. Bot. 66:730-735

37. Rama Rao, P. 1964. Curvularia tuberculata from dune soil. Curr. Sci. 33:121.

38. Santamaria, P. A., Benoit, A., and Mathur, S. B. 1971. Curvularia cymbopogonis: A hitherto unreported species pathogenic to rice in the Philippines. Plant Dis. Rep. 55:349-350.

39. Seshadri, K., Padmanaban, P., and Alexander, K. C. 1980. A new leaf blight disease of sugarcane. Indian Phytopathol. 33:325-326.

40. Sivanesan, A. 1987. Graminicolous species of Bipolaris, Curvularia, Drechslera and Exserohilum and their teleomorphs. Mycol. Pap. 
158:1-261

41. Skoropad, W. R., and Arny, D. C. 1956. Histologic expression of susceptibility and resistance in barley to strains of Helminthosporium gramineum. Phytopathology 46:289292.

42. Sridhar, R., Ou, S. H., and Ebron, S. P. 1972. Lesion development on a rice cultivar by different races of the blast pathogen. Plant Dis. Rep. 56:961-963.

43. Watson, A. K. 1985. Host specificity of plant pathogens in biological weed control. Pages 99-104 in: Proc. Int. Sympos. Biol.Control Weeds, VI. E. S. Delfosse, ed. Agriculture Canada, Ottawa, ON.

44. Watson, A. K. 1994. Current status of bioherbicide development and prospects for rice in Asia. Pages 195-201 in: Integrated Management of Paddy and Aquatic Weeds in Asia. H. Shibayama, K. Kiritani, and J. Bay-Petersen, eds. FFTC Book Series No. 45. Food and Fertilizer Technology Center for the Asian and
Pacific Region, Taipei, Taiwan.

45. Webster, R. K., and Gunnell, P. S., eds. 1992. Compendium of Rice Diseases. American Phytopathological Society, St. Paul, MN.

46. Wheeler, H. 1977. Ultrastructure of penetration by Helminthosporium maydis. Physiol. Plant. Pathol. 11:171-178.

47. Yeh, W. H., and Bonman, J. M. 1986. Assessment of partial resistance to Pyricularia oryzae in six rice cultivars. Plant Pathol. 35:319-323. 